Int. J. Electrochem. Sci., 11 (2016) $9704-9722$

International Journal of

ELECTROCHEMICAL

SCIENCE

Www.electrochemsci.org

\title{
Research on Theoretical Model of Combined Micro-Machining of Laser and Electrolysis of Thermal Barrier Coated Turbine Blade Film Cooling Holes
}

\author{
Aixi Sun ${ }^{1}$, Yulan $\mathrm{Hu}^{2, *}$ and Bo Hao ${ }^{1,3}$ \\ ${ }^{1}$ School of Mechanical Engineering, Nanjing University of Science and Technology, Nanjing 210094, \\ China \\ ${ }^{2}$ School of Information Science and Engineering, Shenyang Ligong University, Shenyang 110159 , \\ China \\ ${ }^{3}$ School of Mechanical Engineering, Shenyang Ligong University, Shenyang 110159, China \\ *E-mail: wghao95@126.com
}

doi: $10.20964 / 2016.11 .38$

Received: 17 May 2016 / Accepted: 6 September 2016 / Published: 10 October 2016

\begin{abstract}
In view of high quality machining demand of thermal barrier coated turbine blade film cooling holes, a new method of combined micro-machining of laser and electrolysis is presented in this thesis. First of all, in electrolyte fluid, micro-holes on thermal barrier coatings are milled by photochemical etching of ultraviolet laser. Moreover, micro-holes on nickel-based alloy blade are etched by high frequency pulsed electrochemical machining. It can manufacture film cooling holes by cold machining. No recast layer and micro-cracks are produced, so machining quality is improved. Meanwhile, the problem that conventional methods of electric machining such as electrochemical machining and electrical discharge machining cann't etch non-conductive coatings is solved. Machining errors are reduced because only one single presetting cutter is needed from hole machining to its final shape. Methods like small clearance machining, side wall insulating tubular electrode and low concentration acidic electrolyte are applied in electrochemical machining to improve machining precision. This thesis analyzes photochemical etching conditions of micro-holes on thermal barrier coatings with ultraviolet laser, process of development and collapse of cavitation bubbles and their functions in laser machining. It puts forward mechanism of high frequency pulsed electrochemical machining of micro-holes on nickel-based alloy blade. And then, mechanism of combined micro-machining is researched. Heat conduction process in macroscopic materials of thermal barrier coatings and potential distribution in machining gap are analyzed by Fourier's law and Laplace Equation respectively. Cooling effects of electrolyte fluid in laser machining and influences of uneven distribution of electrolyte conductivity in electrochemical machining are considered. Theoretical model of combined micro-machining is established, the validity of which is proved by experiment.
\end{abstract}

Keywords: thermal barrier coatings; photochemical etching; film cooling holes; cold machining; theoretical model 


\section{FULL TEXT}

(C) 2016 The Authors. Published by ESG (www.electrochemsci.org). This article is an open access article distributed under the terms and conditions of the Creative Commons Attribution license (http://creativecommons.org/licenses/by/4.0/). 